\title{
Additive Genetic Effects for Resistance to Foliar Powdery Mildew in Strawberry Revealed through Divergent Selection
}

\author{
Colleen Kennedy, Luis F. Osorio, Natalia A. Peres, and Vance M. Whitaker ${ }^{1}$ \\ Gulf Coast Research and Education Center, University of Florida, 14625 CR 672, Wimauma, FL \\ 33598
}

\begin{abstract}
AdDitional IndeX words. Fragaria $\times$ ananassa, fruit breeding, Podosphaera aphanis
Abstract. Powdery mildew (PM) of strawberry (Fragaria sp.) is a ubiquitous, wind-spread disease caused by the obligate parasite Podosphaera aphanis. To control PM, multiple fungicide applications are necessary each season, and none of the major cultivars in Florida have high levels of resistance. Therefore, the objectives of this study were to observe the response to selection and to estimate genetic parameters for PM and related traits in the University of Florida breeding population. In 2010, clonally replicated individuals from seven biparental crosses arising from 11 parents were included in a field trial in which clonally replicated seedlings were evaluated visually for percent coverage of PM mycelium using a modified Horsfall-Barratt scale of 0 to 6. Broad- $\left(\mathrm{H}^{2}\right)$ and narrow-sense $\left(\mathrm{h}^{2}\right)$ heritabilities for $\mathrm{PM}$ score were (mean $\pm \mathrm{SE}) 0.50 \pm 0.08$ and $0.40 \pm 0.39$, respectively, for the base population. After the second round of selection in the resistant population, no additive variance was detected, indicating that alleles for $P M$ resistance had become fixed. In contrast, after two rounds of divergent selection in the susceptible population, there remained considerable additive variance $\left(h^{2}=0.42 \pm 0.65\right)$. Moderate to high heritability estimates and a clear response to selection indicate that resistance to $P M$ is genetically controlled through mostly additive effects. Selection of parents based on field trials with natural inoculum should result in good progress toward more resistant cultivars. The consistently moderate to strong genotypic and genetic correlations among PM and canopy density (CD) indicate that selection for $P M$ resistance will result in reduced $C D$. Therefore, $C D$ must be monitored over successive rounds of selection for low levels of PM to prevent CD falling below the commercially acceptable range.
\end{abstract}

The Florida strawberry industry supplies the eastern United States and Canada with strawberries from November through March. A highly intensified annual growing system combined with humid conditions throughout much of the season gives rise to many cultural challenges, particularly the control of fungal diseases. One such disease is powdery mildew, which has been observed in all parts of the world where strawberries are grown (Peries, 1962). PM diseases are caused by different species of fungi in the family Erysiphaceae. PM diseases have been commonly reported in cereals such as wheat (Triticum aestivum) and barley (Hordeum vulgare), cucurbits (Cucurbitaceae), sugar beet (Beta vulgaris), clover (Trifolium sp.), ornamentals, grape (Vitis vinifera), apple (Malus $\times$ domestica), and oak (Quercus sp.) (Agrios, 1997). Strawberry PM is caused by the obligate parasite Podosphaera aphanis (formerly Sphaerotheca macularis).

Podosphaera aphanis conidia are primarily wind-spread (Blanco et al., 2004; Strand, 2008), and dispersal is inhibited by free water (Blanco et al., 2004; Peries, 1962; Strand, 2008) such as rain or overhead irrigation. Rainfall washes conidia from the air, decreasing spore concentrations (Blanco et al., 2004). Also, free water inhibits sporulation of colonies on the leaf surface (Peries, 1962), inhibits conidial germination, and reduces mycelia growth (Jhooty and McKeen, 1965). Powdery mildew of strawberry affects all above-ground organs including leaves, stolons, flowers, and fruit (Peres and Mertely, 2009). When $P$. aphanis infects flowers, fruit may become malformed or aborted (Peres and Mertely, 2009). Severely infected plants

Received for publication 7 Jan. 2014. Accepted for publication 3 Mar. 2014. ${ }^{1}$ Corresponding author. E-mail: vwhitaker@ufl.edu. have reduced vigor (Daubeny, 1961), and late-season infection of ripening fruit can cause substantial crop loss (Horn et al., 1972).

In Florida, PM can be controlled, to some degree, through the use of disease-free transplants; however, multiple applications of fungicides are necessary in many seasons (Maas, 1998). This disease is expected to have an increased impact in Florida in the future as a result of the expanded use of protected culture systems such as high tunnels and rowcovers, which are being used as alternatives to overhead irrigation for freeze protection. As a result of the lack of free water in these production systems, conditions are favorable for development of $P$. aphanis (Xiao et al., 2001). Additionally, because high tunnels and rowcovers can provide season extension/optimization, these systems are highly used worldwide, including many regions where University of Florida cultivars are grown (Hancock and Simpson, 1995; Ogden and van Iersel, 2009; Salame-Donoso et al., 2010). The leading commercial cultivars in Florida do not have high PM resistance. The most widely grown cultivars in Florida over the last decade, Strawberry Festival (Chandler et al., 2000) and Florida Radiance (Chandler et al., 2009), are characterized as susceptible to this disease (Peres and Mertely, 2009; N.A. Peres and T. Seijo, personal communication).

Quantitative genetic parameters have been estimated for resistance to PM of strawberry in multiple previous studies. Nelson et al. (1995) estimated broad- and narrow-sense heritabilities for PM incidence and severity in greenhouse and in open-field environments in California. Based on 17 full-sib families from a half-diallel crossing scheme, they reported broad-sense heritabilities for disease incidence of $\mathrm{H}^{2}=0.44$ in a Watsonville, CA, field trial and $\mathrm{H}^{2}=0.71$ in the greenhouse. 
Heritabilities were higher for disease severity at $\mathrm{H}^{2}=0.70$ to 0.72 and $\mathrm{H}^{2}=0.94$ for the fields and greenhouse, respectively. However, in the Watsonville trial, narrow-sense heritabilities were estimated at only $h^{2}=0.15$ and 0.12 for incidence and severity. In the greenhouse, where disease severity was higher, estimates were $h^{2}=0.71$ for disease incidence and $h^{2}=0.90$ for severity.

In Norway, Davik and Honne (2005) conducted an experiment to estimate genetic variances for resistance to PM of strawberry based on an incomplete 63-by-63 partial diallel mating design with 298 full-sib families planted in six field locations. Heritability estimates were intermediate, $\mathrm{H}^{2}=0.44$ and $\mathrm{h}^{2}=0.39$. When pedigree information was included in the model, heritability estimates increased to $\mathrm{H}^{2}=0.50$ and $\mathrm{h}^{2}=$ 0.45 , mainly as a result of an increase in the additive genetic component. Lifshitz et al. (2007) later conducted a replicated greenhouse experiment indicating similar levels of repeatability $\left(\mathrm{H}^{2}=0.46\right.$ to 0.56$)$, although narrow-sense estimates were not estimated in this study.

Heritability estimates for most of these studies were in the intermediate to high range, which indicates potential for genetic gains using recurrent selection methodologies. However, these studies also suggest that heritability estimates are characteristic of individual populations and environments. Furthermore, genetic parameters may change over time as populations become more or less genetically diverse and undergo selection pressure. To date, there have been no published reports on the inheritance of PM resistance in the Florida strawberry breeding population.

There is evidence to suggest that plant growth and architecture influence PM disease development. A positive relationship was found between PM development and vigorous, highly vegetative plants in grape (Valdes-Gomez et al., 2011), which may be the result of microclimate effects of temperature, relative humidity (RH), or solar irradiance (Pangga et al., 2013; Zahavi et al., 2001). RH above 75\% (Jhooty and McKeen, 1965) is essential for the germination of $P$. aphanis conidia. Several researchers have reported that increased exposure to ultraviolet irradiance significantly suppressed PM diseases (Keller et al., 2003; Suthaparan et al., 2012; Willocquet et al., 1996). Therefore, higher humidity and lower levels of ultraviolet light within a dense plant canopy may create ideal conditions for PM. Canopy density varies widely among strawberry cultivars and is a potentially correlated trait with PM resistance. Thus far, there are no reports on the genetic relationship between these two traits in strawberry.

The selection of populations in opposite directions is known as two-way or divergent selection with each population serving as a control for the other. Asymmetrical responses in divergent selection experiments can elucidate underlying genetic influences such as random drift, inbreeding depression, maternal effects, and indirect selection (Falconer and Mackay, 1996). Correlated traits can also be revealed by divergent selection. In divergent selection experiments for early- and late-phase change in maize (Zea mays), late-phase change lines were significantly more susceptible to common rust [Puccinia sorghi (Basso et al., 2008)] and feeding damage by european corn borer [Ostrinia nubilalis (Riedeman et al., 2008)] than their counterpart, the early-phase change lines. In addition, comparing heritability estimates from the base population with those based on response to selection allows a better prediction of short-term selection response and the efficiency of the selection strategy (Shaw et al., 1988). Observing selection response can also identify errors arising from parameter estimation, response variable measurement, undefined genotype $\times$ environment, and/ or model assumptions (Pringle and Shaw, 1998). For example, after one round of divergent selection for fruit color in strawberry, Shaw and Sacks (1995) found substantial dominance variance that was not detected in the base population.

The primary objectives of the present study were to estimate genetic parameters for PM resistance in the Florida strawberry breeding population and to examine the potential interactions of this trait with CD. To achieve these goals, a divergent selection experiment was conducted over three seasons to observe response to selection and improve breeding strategies for PM resistance in the University of Florida strawberry germplasm.

\section{Materials and Methods}

FiEld SETting. Field experiments were conducted at the University of Florida Gulf Coast Research and Education Center (GCREC) at Balm, FL (lat. 2745'37.98" N, long. $\left.82^{\circ} 13^{\prime} 32.49^{\prime \prime} \mathrm{W}\right)$ during the 2009-10, 2011-12, and 2012-13 seasons. Strawberry plants were grown on raised beds formed 4 to 6 weeks before planting that were $71 \mathrm{~cm}$ wide at the base, $61 \mathrm{~cm}$ wide at the top, and $25 \mathrm{~cm}$ high. Beds were fumigated $\approx 1$ month before planting with a mixture of $1,3 \mathrm{D}$-dichloropropene and chloropicrin according to current commercial standards and covered in black high-density polyethylene mulch. Two rows of planting holes were punched per bed with a $38-\mathrm{cm}$ inrow spacing and $28 \mathrm{~cm}$ between rows. After transplant, bareroot runner plants were overhead-irrigated for $10 \mathrm{~d}$ during daylight hours to facilitate establishment. Once established, plants were irrigated through the drip tape twice per day with one irrigation between 0800 and $0900 \mathrm{HR}$ and another between 1300 and $1400 \mathrm{HR}$ with durations of between 30 and 60 min depending on time of year, age of the plants, and water availability. Fertigation was applied through drip tape beginning $10 \mathrm{~d}$ after transplanting. Fertilization and pest control followed current crop recommendations for strawberry in Florida (Santos et al., 2011); however, no products were applied to control PM.

Base Population DeVelopment. In Jan. 2009, a base population was constructed consisting of seven full-sib families derived from biparental crosses of 11 parents from the main breeding population at University of Florida. The seven families were selected as a random subset of families generated in the breeding program that year; nine parents were advanced breeding selections and one parent arose from a cross between an advanced breeding selection and a wild accession of $F$. virginiana ssp. glauca collected from southern Colorado for its apparent day neutrality (Table 1). This population is further described in other studies (Hasing et al., 2012, 2013; Whitaker et al., 2012). Controlled pollinations were conducted in the greenhouse; when ripe, the achenes were removed from the receptacle using an electric blender. Seeds were allowed to dry overnight and stored in vials at $4{ }^{\circ} \mathrm{C}$ until sowing.

Before sowing, the seeds were scarified in concentrated sulfuric acid for $15 \mathrm{~min}$ and rinsed three times in running water. The seeds were sown in Apr. 2009 on the surface of moist, peatbased media (Fafard 2 Mix; Fafard, Agawam, MA) in open trays under intermittent mist. Germination occurred within 4 to 6 weeks and the seedlings were transferred to peat pellets in May 2009. In June 2009, the seedlings were transported to the breeding program's summer nursery site near Monte Vista, CO 
Table 1. Number of strawberry parents and number of evaluated fullsib families and clones (genotypes) arising from those parents for a base population (2009-10) and subsequent populations created through divergent selection in the resistant $(\mathrm{R})$ and susceptible $(\mathrm{S})$ directions for foliar powdery mildew (PM) resistance (2011-12 and 2012-13). ${ }^{\mathrm{z}}$

\begin{tabular}{|c|c|c|c|c|c|}
\hline & \multirow{2}{*}{$\begin{array}{c}\text { Base population } \\
\text { (no.) }\end{array}$} & \multicolumn{2}{|c|}{$2011-12$} & \multicolumn{2}{|c|}{$2012-13$} \\
\hline & & $\overline{\mathrm{R} \text { (no.) }}$ & S (no.) & $\overline{\mathrm{R} \text { (no.) }}$ & S (no.) \\
\hline Parents & 11 & 6 & 6 & 6 & 6 \\
\hline Full-sib families & 7 & 14 & 16 & 8 & 11 \\
\hline Clones & 633 & 247 & 280 & 83 & 129 \\
\hline Clonal replicates & 2532 & 988 & 1120 & 332 & 516 \\
\hline
\end{tabular}

${ }^{\mathrm{z}}$ The total number of clonal replicates (individual plants) evaluated is also shown.

(lat. $37^{\circ} 40^{\prime} 46.10^{\prime \prime} \mathrm{N}$, long. $106^{\circ} 8^{\prime} 10.83^{\prime \prime} \mathrm{W}$ ) where they were clonally propagated by runners. Four bare-root runner plants (ramets) from each seedling were dug from the breeding program's summer nursery site in late September and shipped to GCREC for planting in the field. The ramets were planted in the field in early October and organized in a modified Latin square design with four replications of single-plant plots with three raised beds per replication.

Data collection. The trials relied on naturally occurring inoculum and were monitored after planting to determine the optimal time to perform ratings. Ratings for PM were initiated when the abaxial leaf surfaces of the most susceptible genotypes were nearly $100 \%$ covered with mycelia. Each plant was inspected by gently turning and laying over the entire bulk of stems and leaves to expose the abaxial surfaces of the leaves. The percent coverage of PM mycelia on the abaxial surface of fully expanded trifoliate leaves was rated subjectively using a modified Horsfall-Barratt scale of 0 to 6 where $0=0 \%$ to $1 \%$ coverage, $1=2 \%$ to $10 \%, 2=11 \%$ to $25 \%, 3=26 \%$ to $50 \%, 4=$ $51 \%$ to $75 \%, 5=76 \%$ to $95 \%$, and $6=96 \%$ to $100 \%$ coverage (Horsfall and Barratt, 1945). CD was rated on a scale of 1 to 5 where $1=$ very open and $5=$ very dense. The base population was rated for PM between 28 Jan. and 7 Mar. 2010 and CD was rated on 25 Jan. 2010.

Divergent Selection. After ratings were complete in the first season, parents were selected based on phenotype for inclusion in two mating designs. Because 12 total parents were to be selected, only six of the seven full-sib families (selected randomly) were used for parent selection. Within each of the six full-sib families, one parent was selected from the most resistant $10 \%$ of individuals and one parent was selected from the most susceptible $10 \%$. This selection scheme avoided fullsib matings and potential inbreeding depression in the progeny. Although directional selection was performed for PM, stabilizing selection was performed for $\mathrm{CD}$ to restrict $\mathrm{CD}$ to a commercially realistic range. Therefore, the 12 selected parents were chosen to have CD ratings ranging from 2.3 to 3.7 .

Runner tips from the parental selections were collected from the field in Apr. 2010 and rooted under intermittent mist for 4 to 5 weeks in a greenhouse at the GCREC. Rooted tips were transplanted into soilless media (Fafard 2 Mix) in 3.8-L pots as mother plants for further propagation. To make plants for greenhouse crosses, tips were collected from the mother plants in Sept. 2010 and propagated as previously described. In Jan. 2011 , controlled crosses were conducted in the greenhouse in which the selected parents were mated in circular diallel mating designs (example shown in Kayihan et al., 2005) within resistant and susceptible classes resulting in 30 full-sib families (Table 1). Seed germination and summer propagation were conducted as previously described.

On 7 Oct. 2011, four ramets per seedling were planted in the field in a randomized complete block with two beds per replication and grown as previously described. Plants were rated in Jan. 2012 for PM and CD according to the methods used for the base population. After rating, parents were once again selected (based on phenotype) divergently for PM with stabilizing selection for CD. Six genotypes from the most resistant $10 \%$ of individuals in the resistant population were chosen as parents, one from each of six full-sib families, and likewise for the susceptible population. Controlled pollinations for the second round of divergent selection were conducted in the field rather than in the greenhouse to speed the process and evaluate the progeny in the subsequent season. As before, the parents were mated in circular diallels within resistant and susceptible classes resulting in 19 full-sib families. Because field crossing resulted in reduced seed set and germination rates, the number of individuals available for testing in the next generation was lower (Table 1). Seeds were germinated and seedlings were clonally propagated in the summer nursery as previous described. For the final round of evaluation, four ramets from each seedling were transplanted to the field on 27 Sept. 2012 and arranged in a randomized complete block with four replications with one bed per replication and grown as previously described. Ratings for PM and CD were conducted in Jan. 2013 as previously described.

STATISTICAL ANALYSIS. Univariate and bivariate analyses for PM and CD were conducted using ASReml software (Gilmour et al., 2009). For each of the populations, a univariate analysis incorporating 13 generations of pedigree information was performed according to the following linear mixed model:

$$
y=\mathrm{X} b+\mathrm{Z}_{1} a+\mathrm{Z}_{2} f+\mathrm{Z}_{3} c+e
$$

where $y$ is the vector of observations corresponding to either trait 1 (PM) or 2 (CD), $b$ is the vector of fixed effects (mean and replications), $a$ is the vector of random genotype (clone) effects $\sim N I D\left(0, A \sigma_{a}^{2}\right)$ where $A$ is the numerator relationship matrix and $\sigma_{a}^{2}$ accounts for all the additive variance, $f$ is the matrix of random full-sib family effects $\sim N I D\left(0, I \sigma_{f}^{2}\right)$ and $\sigma_{f}^{2}$ accounts for one-fourth of the dominance variance, $c$ is the matrix of random remainder non-additive genetic effects of clone within family $\sim N I D\left(0, I \sigma_{c}^{2}\right)$, and $\mathrm{e}$ is the vector of random residual effects $\sim \operatorname{NID}\left(0, \sigma_{e}^{2}\right)$, where $\mathrm{I}$ is an identity matrix, $X$ is the incidence matrix for fixed effects, and $Z_{1}, Z_{2}$, and $Z_{3}$ are incidence matrices for random effects.

Univariate analyses were performed to generate variance components for the bivariate analysis and for the estimation of narrow-sense and broad-sense heritabilities. Estimates of $h^{2}$ and $\mathrm{H}^{2}$ were calculated according to the following formulas:

$$
\begin{aligned}
h^{2} & =\frac{\sigma_{a}^{2}}{\sigma_{a}^{2}+\sigma_{f}^{2}+\sigma_{c}^{2}+\sigma_{e}^{2}} \\
H^{2} & =\frac{\sigma_{a}^{2}+\sigma_{f}^{2}+\sigma_{c}^{2}}{\sigma_{a}^{2}+\sigma_{f}^{2}+\sigma_{c}^{2}+\sigma_{e}^{2}}
\end{aligned}
$$

Bivariate analyses provided variance-covariance estimates to calculate phenotypic, total genetic, and additive correlations 
between the two traits. A similar mixed model to the one in Eq. [1] was used, where y is a stacked vector for both PM and $\mathrm{CD}$ traits, $a \sim \operatorname{MVN}(0, G \otimes A)$ where a $G$ is the variancecovariance matrix of additive effects for both traits and $A$ is the numerator relationship matrix, $f \sim M V N(0, D \otimes I)$ and $D$ is the variance-covariance matrix of dominance effects, $c \sim \operatorname{MVN}(0, C \otimes I)$ and $C$ is the variance-covariance matrix of the remaining random non-additive genetic effects, $e \sim \operatorname{MVN}(0, R)$, and $R$ is the variance-covariance matrix of the residual effects for both traits. $I$ is an identity matrix, $b, a, f$, and $e$, as well as $\mathrm{I}, Z_{1}, Z_{2}$, and $Z_{3}$ have been previously defined. The additive $\left(r_{a}\right)$, total genetic $\left(r_{g}\right)$, and phenotypic $\left(r_{p}\right)$ correlations among traits were estimated according to the following equations:

$$
\begin{aligned}
& r_{p}=\frac{\sigma_{a_{(P M, C D)}}+\sigma_{f_{(P M, C D)}}+\sigma_{c_{(P M, C D)}}+\sigma_{e_{(P M, C D)}}}{\sqrt{\begin{array}{c}
\left(\sigma_{a_{(P M)}}^{2}+\sigma_{f_{(P M)}}^{2}+\sigma_{c_{(P M)}}^{2}+\sigma_{e_{(P M)}}\right) \\
\times\left(\sigma_{a_{(C D)}}^{2}+\sigma_{f_{(C D)}}^{2}+\sigma_{c_{(C D)}}^{2}+\sigma_{e_{(C D)}}\right)
\end{array}}} \\
& r_{g}=\frac{\sigma_{a_{(P M, C D)}}+\sigma_{f_{(P M, C D)}}+\sigma_{c_{(P M, C D)}}}{\sqrt{\left(\sigma_{a_{(P M)}}^{2}+\sigma_{f_{(P M)}}^{2}+\sigma_{c_{(P M)}}^{2}\right) \times\left(\sigma_{a_{(C D)}}^{2}+\sigma_{f_{(C D)}}^{2}+\sigma_{c_{(C D)}}^{2}\right)}}
\end{aligned}
$$

$$
r_{a}=\frac{\sigma_{a_{(P M, C D)}}}{\sqrt{\sigma_{a_{(P M)}}^{2} \times \sigma_{a_{(C D)}}^{2}}}
$$

Predicted response was calculated with the following equation:

$$
R_{p}=h^{2} S
$$

where $S$, the selection differential, is defined as the average difference between the clonal mean of the parental generation and the clonal mean of the selected parents and $h^{2}$ is the estimate from the base population. Observed response was calculated according to the following equation:

$$
R_{o}=\mu_{p}-\mu_{l}
$$

where $\mu_{p}=$ population mean of the current generation and $\mu_{l}=$ population mean of the previous generation. Realized heritability was calculated according to the following equation:

$$
h_{r}^{2}=\frac{R_{o}}{S}
$$

The inbreeding coefficients were calculated as the diagonal of $A-I$ matrix within ASReml software using the !DIAG qualifier.

\section{Results}

Substantial, heritable genetic variation was estimated for PM resistance in the base population. Heritabilities for PM score were (mean $\pm \mathrm{SE}) \mathrm{H}^{2}=0.50 \pm 0.08$ and $\mathrm{h}^{2}=0.40 \pm 0.39$, indicating that resistance to PM is under genetic control and consists primarily of additive variance (Table 2). The base population mean PM score was 3.16 with full-sib family means ranging from 1.8 to 4.0 . For the resistant population in the first round of divergent selection, heritabilities for PM score were $\mathrm{H}^{2}=$ $0.64 \pm 0.07$ and $h^{2}=0.60 \pm 0.22$, but, by the second round, there was no additive variance detected (Table 2). For the first round in the susceptible population, heritabilities for PM score were $\mathrm{H}^{2}=$ $0.68 \pm 0.03$ and $h^{2}=0.64 \pm 0.04$ (Table 2). In contrast to the resistant population, after two rounds of divergent selection in the susceptible population, there remained considerable additive variance $\left(\mathrm{h}^{2}=0.42 \pm 0.65\right)$ (Table 2$)$. The means for the resistant and susceptible seedling populations arising from the first round of divergent selection were 1.76 and 3.73, respectively, and for the second round were 0.24 and 4.45, respectively (Fig. 1).

In the resistant population during the first round of selection, the observed response to selection was greater than the predicted response, resulting in larger realized heritability compared with the estimate. Conversely, in the susceptible population, the observed response to selection was less than the predicted response, resulting in lower realized heritability compared with the estimate (Table 2). A similar trend of the observed response to selection compared with the predicted response was obtained in the second round of selection, but the realized heritabilities for the resistant and susceptible populations could not be estimated as a result of this being the last round of selection.

Inbreeding coefficients for full-sib families for the base

\begin{tabular}{|c|c|c|c|c|c|}
\hline & \multirow[b]{2}{*}{ Base population $^{z}$} & \multicolumn{2}{|c|}{ 2011-12 } & \multicolumn{2}{|c|}{$2012-13$} \\
\hline & & $\mathrm{R}$ & $\mathrm{S}$ & $\mathrm{R}$ & $\mathrm{S}$ \\
\hline $\mathrm{h}^{2}( \pm \mathrm{SE})$ & $0.40 \pm 0.39$ & $0.60 \pm 0.22$ & $0.65 \pm 0.03$ & $0.00 \pm 0.00$ & $0.42 \pm 0.65$ \\
\hline $\mathrm{R}_{\mathrm{p}}$ & $-^{\mathrm{y}}$ & -1.04 & 0.82 & -1.06 & 1.40 \\
\hline $\mathrm{R}_{\mathrm{o}}$ & - & -1.39 & 0.58 & -1.52 & 0.72 \\
\hline $\mathrm{R}_{\mathrm{o}} / \mathrm{R}_{\mathrm{p}}$ & - & 1.34 & 0.70 & 1.44 & 0.51 \\
\hline$F_{f}$ & $11.0 \%$ & $13.1 \%$ & $14.9 \%$ & $18.8 \%$ & $23.8 \%$ \\
\hline
\end{tabular}
population were $11.0 \%$ on average. The inbreeding coefficients increased for the susceptible and for the resistant populations

Table 2. Broad- $\left(\mathrm{H}^{2}\right)$ and narrow-sense $\left(h^{2}\right)$ heritabilities, realized heritability $\left(h_{r}^{2}\right)$, predicted response to selection $\left(R_{p}\right)$, observed response to selection $\left(\mathrm{R}_{\mathrm{o}}\right)$, and mean inbreeding coefficient for parents $\left(\mathrm{F}_{\mathrm{p}}\right)$ and full-sib families $\left(\mathrm{F}_{\mathrm{f}}\right)$ for a strawberry base population and after two rounds of divergent selection [resistant $(\mathrm{R})$ and susceptible $(\mathrm{S})$ populations] for foliar powdery mildew resistance in Balm, FL.

${ }^{\mathrm{z}^{2}}{ }_{\mathrm{r}}, \mathrm{F}_{\mathrm{p}}$, and $\mathrm{F}_{\mathrm{f}}$ are the mean values of the two estimates based on the resistant and susceptible populations in 2011-12.

yparameter not estimable. 

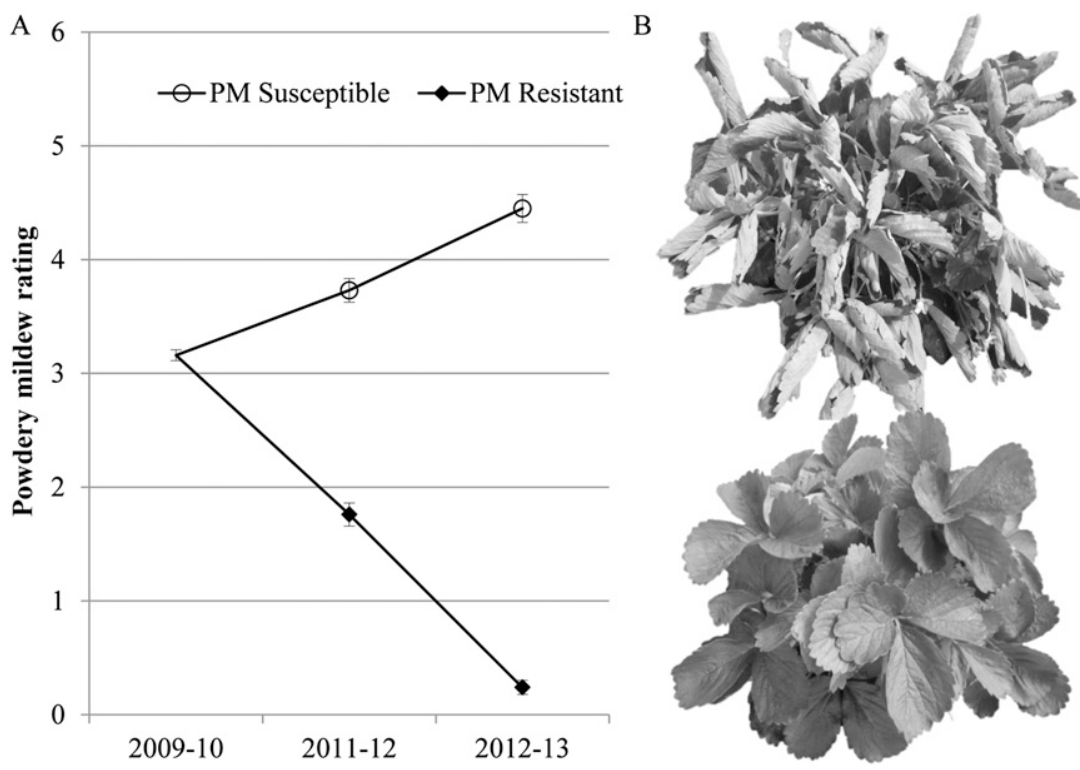

Fig. 1. Mean foliar powdery mildew (PM) rating of strawberry populations beginning with the unselected base population (2009-10) and after two rounds of divergent selection (2011-12 and 2012-13) with bars representing SE based on clonal means (A). Images (B) illustrate the disease rating scale (0 to 6), where the genotype pictured at the top received a rating of six (96\% to $100 \%$ mycelia coverage) and the genotype pictured at the bottom received a rating of zero ( $0 \%$ to $1 \%$ mycelia coverage).

under divergent selection. The values of the inbreeding coefficients for the susceptible population after two rounds of selection $(14.9 \%$ and $23.8 \%)$ appeared comparable to those of the resistant population (13.1\% and $18.8 \%$ ) (Table 2).

Heritability estimates for $\mathrm{CD}$ in the base population were (mean $\pm \mathrm{SE}$ ) $\mathrm{H}^{2}=0.25 \pm 0.06$ and $\mathrm{h}^{2}=0.13 \pm 0.18$ (Table 3). After one round of selection, the heritabilities for the resistant population were $\mathrm{H}^{2}=0.42 \pm 0.05$ and $\mathrm{h}^{2}=0.16 \pm 0.13$ and for the susceptible population were $\mathrm{H}^{2}=0.47 \pm 0.06$ and $\mathrm{h}^{2}=0.21 \pm$ 0.17 (Table 3). After the final round of selection, the heritabilities for the resistant and susceptible population were $\mathrm{H}^{2}=$ $0.40 \pm 0.08$ and $\mathrm{h}^{2}=0.33 \pm 0.10$ and $\mathrm{H}^{2}=0.39 \pm 0.10$ and $\mathrm{h}^{2}=$ $0.31 \pm 0.22$, respectively (Table 3 ). Broad-sense heritability estimates for CD increased in the PM-resistant and in the PMsusceptible populations after the first round of selection and remained fairly stable after the second round of selection; however, estimates of narrow-sense heritability remained unchanged.

There were positive phenotypic, genotypic, and additive correlations between the PM resistance and CD traits (Table 4). The phenotypic and additive correlations remained relatively unchanged over time with greater fluctuations observed in the genotypic correlations (Table 4). Moderate to high and positive genotypic and additive correlations suggest that some of the same genetic loci contribute to PM resistance and to low CD.

\section{Discussion}

There was a strong selection response for PM in both directions that was consistent with the high level of additive genetic variance estimated in the base population. This indicates that parent selection in a breeding program based on field ratings under naturally occurring inoculum should result in steady gains over time. The experiment was purposefully conducted over 3 years to expose the plant population to a potentially variable pathogen population. Pathogenic races have been identified in fungal species causing PM in cucurbits (Jahn et al., 2002), rose [Rosa sp. (Linde and Debener, 2003)], and wheat (Hsam and Zeller, 2002). Racespecific resistance has also been reported in grape (Ramming et al., 2012). However, it is not conclusively known whether pathogenic races exist for $P$. aphanis. Xu et al. (2008) tested 12 isolates on a number of commercial strawberry cultivars and found no significant race-specific interactions.

The realized response to selection in the resistant direction was greater than predicted in both cycles but was less than predicted in the susceptible direction (Table 2). Heritabilities can increase or decrease with selection depending on initial allele frequencies and types of genetic effects (Falconer and Mackay, 1996). The asymmetrical response observed may be partially the result of asymmetric allelic frequencies at the segregating loci in the base population (Burgess et al., 2007; Landi et al., 2001; Shaw et al., 1997). In other words, a greater frequency of resistant alleles with additive effects at the causal loci compared with susceptible alleles could result in a greater response to selection in the resistant direction.

In the final round of selection in the resistant direction, the narrow-sense heritability was 0.00 , which indicates no remaining additive variance. However, the broad-sense heritability was 0.65 . When phenotypic variation is very low, any variance among clones within a family will give an estimate of broadsense heritability, and this needs to be taken into account when interpreting these results. Although the result of zero additive variance should be taken with some caution, the dramatic reduction of additive variance, along with a population mean approaching zero (Fig. 1), is consistent with maximum response or fixation. When the population size is not large, inbreeding may contribute to fixation of alleles. However, the mating design, a circular diallel with no self or full-sib crosses, was used to reduce inbreeding. Given that inbreeding coefficients were relatively low and only rose by $5.7 \%$ in the final round of selection, it seems unlikely that inbreeding on the

Table 3. Broad- $\left(\mathrm{H}^{2}\right)$ and narrow-sense $\left(\mathrm{h}^{2}\right)$ heritabilities for canopy density $(\mathrm{CD})$ in a strawberry base population and after two rounds of divergent selection for foliar powdery mildew in the resistant $(\mathrm{R})$ and susceptible (S) directions and stabilizing selection for CD in Balm, FL.

\begin{tabular}{|c|c|c|c|c|c|}
\hline & \multirow[b]{2}{*}{ Base population } & \multicolumn{2}{|c|}{$2011-12$} & \multicolumn{2}{|c|}{$2012-13$} \\
\hline & & $\mathrm{R}$ & $\mathrm{S}$ & $\mathrm{R}$ & $\mathrm{S}$ \\
\hline$\overline{\mathrm{H}^{2}( \pm \mathrm{SE})}$ & $0.25 \pm 0.06$ & $0.42 \pm 0.05$ & $0.47 \pm 0.06$ & $0.40 \pm 0.08$ & $0.39 \pm 0.10$ \\
\hline $\mathrm{h}^{2}( \pm \mathrm{SE})$ & $0.13 \pm 0.18$ & $0.18 \pm 0.13$ & $0.22 \pm 0.16$ & $0.33 \pm 0.10$ & $0.31 \pm 0.22$ \\
\hline
\end{tabular}


Table 4. Phenotypic $\left(r_{\mathrm{p}}\right)$, total genetic $\left(r_{\mathrm{g}}\right)$, and additive genetic $\left(r_{\mathrm{a}}\right)$ correlations of foliar powdery mildew resistance and plant canopy density in a strawberry base population (2009-10) and after two rounds of divergent selection (2011-12 and 2012-13) for foliar powdery mildew resistance in Balm, FL.

\begin{tabular}{lccc}
\hline & $2009-10$ & $2011-12$ & $2012-13$ \\
\hline$r_{\mathrm{p}}( \pm \mathrm{SE})$ & $0.24 \pm 0.07$ & $0.20 \pm 0.08$ & $0.28 \pm 0.11$ \\
$r_{g}( \pm \mathrm{SE})$ & $0.61 \pm 0.12$ & $0.27 \pm 0.13$ & $0.41 \pm 0.18$ \\
$r_{\mathrm{a}}( \pm \mathrm{SE})$ & $0.88 \pm 0.10$ & $0.49 \pm 0.27$ & $0.60 \pm 0.30$ \\
\hline
\end{tabular}

population level was important compared with the role of selection in fixing alleles for resistance (Table 2).

After the final round of parental selection, a pedigree was constructed, which revealed that all of the resistant parents selected shared the same great-great-grandparent, a wild Fragaria virginiana ssp. glauca accession collected by the GCREC breeding program staff in Colorado named Rock Creek, indicating that this genotype could be a major source of the observed resistance. Although this accession was not formally screened for powdery mildew resistance as part of this study, PM has been noted on this genotype in multiple years at GCREC (V. Whitaker, personal observation). Therefore, any resistance conferred through Rock Creek may be recessive. In barley, homozygous recessive mlo alleles confer resistance to powdery mildew (Lyngkjaer et al., 2000). When a homolog (PpMlo1) of the barley resistance gene from peach (Prunus persica) was expressed in antisense orientation in Fragaria $\times$ ananassa LF9, resistance to P. aphanis was conferred (Jiwan et al., 2013). Because mlo resistance is caused by a lack of expression of the Mlo allele, the authors suggested that silencing PpMlo1 had a similar effect in strawberry. Recessive resistance in the base population would be consistent with the observed asymmetrical response to selection, because recessive resistance alleles would be expected to proceed to fixation more rapidly than dominant alleles.

The consistently moderate to strong genotypic and genetic correlations among PM and CD indicate that selection for PM resistance will result in reduced canopy density and vice versa. The additive correlation $\left(r_{a}\right)$ between traits in the second round of selection is the result of the correlation between susceptible genotypes because the additive variation for the resistant genotypes is close to zero. Therefore, CD must be monitored over successive rounds of selection for low levels of PM or CD may fall below commercially acceptable ranges. Genotypes with $\mathrm{CD}$ ratings below 2.5 are not likely to have sufficient plant robustness for commercial strawberry production. Correlations among PM and CD may be the result of linkage or possibly the result of pleiotropy if a common set of genes control these traits (Landi et al., 2001; Stowe and Marquis, 2011; Wolff and Vandelden, 1989). For instance, genes conferring low-density or "open" plant canopies will also indirectly confer microclimates in the plant with reduced free water and humidity, which will further promote a reduction in PM incidence and severity. The fluctuations in genetic correlation estimates over generations between these two traits may have resulted from changes in variance within full-sib families over the course of selection or may simply reflect the fact that genetic correlations are difficult to estimate with precision (Collins et al., 1998). Falconer and Mackay (1996) emphasize that selection may change patterns of correlation between traits quite significantly.

\section{Conclusions}

Considering the overall moderate to high heritability estimates and clear response to selection for two generations, we conclude that resistance to PM is genetically controlled through mostly additive effects. Through field selection based on natural infection and traditional breeding techniques, good progress can be made toward developing strawberry cultivars with resistance to PM. Final selections were made from the resistant population for use as parents. These selections exhibited high levels of PM resistance and desirable plant architecture and fruit color and size, which were much improved over the wild genetic background shared by the resistant selections.

\section{Literature Cited}

Agrios, G.N. 1997. Plant pathology. 5th Ed. Elsevier Academic Press, Burlington, MA.

Basso, C.F., M.M. Hurkman, E.S. Riedeman, and W.F. Tracy. 2008. Divergent selection for vegetative phase change in maize and indirect effects on response to Puccinia sorghi. Crop Sci. 48:992999.

Blanco, C., B. de los Santos, C. Barrau, F.T. Arroyo, M. Porras, and F. Romero. 2004. Relationship among concentrations of Sphaerotheca macularis conidia in the air, environmental conditions, and the incidence of powdery mildew in strawberry. Plant Dis. 88:878881.

Burgess, K.S., J.R. Etterson, and L.F. Galloway. 2007. Artificial selection shifts flowering phenology and other correlated traits in an autotetraploid herb. Heredity 99:641-648.

Chandler, C.K., D.E. Legard, D.D. Dunigan, T.E. Crocker, and C.A. Sims. 2000. 'Strawberry Festival' strawberry. HortScience 35:13661367.

Chandler, C.K., B.M. Santos, N.A. Peres, C. Jouquand, A. Plotto, and C.A. Sims. 2009. 'Florida Radiance' strawberry. HortScience 44:1769-1770.

Collins, R.P., M.T. Abberton, T.P.T. Michaelson-Yeates, A.H. Marshall, and I. Rhodes. 1998. Effects of divergent selection on correlations between morphological traits in white clover (Trifolium repens L.). Euphytica 101:301-305.

Daubeny, H.A. 1961. Powdery mildew resistance in strawberry progenies. Can. J. Plant Sci. 41:239-243.

Davik, J. and B.I. Honne. 2005. Genetic variance and breeding values for resistance to a wind-borne disease Sphaerotheca macularis (Wallr. ex Fr.) in strawberry (Fragaria $\times$ ananassa Duch.) estimated by exploring mixed and spatial models and pedigree information. Theor. Appl. Genet. 111:256-264.

Falconer, D.S. and T.F.C. Mackay. 1996. Introduction to quantitative genetics. 4th Ed. Pearson Education, Harlow, UK.

Gilmour, A.R., B.J. Gogel, B.R. Cullis, and R. Thompson. 2009. ASReml user guide release 3.0. 15 Nov. 2013. <http://www.vsni. co.uk>.

Hancock, J. and D. Simpson. 1995. Methods of extending the strawberry season in Europe. HortTechnology 5:286-290.

Hasing, T., L.F. Osorio, and V.M. Whitaker. 2012. Estimation of genetic parameters and gains for color traits of strawberry. Euphytica 186:303-311.

Hasing, T.N., L.F. Osorio, and V.M. Whitaker. 2013. Within-season stability of strawberry soluble solids content. J. Amer. Soc. Hort. Sci. 138:190-197.

Horn, N.L., K.R. Burnside, and R.B. Carver. 1972. Powdery mildew of strawberry. Plant Dis. Rptr. 56:368.

Horsfall, J.G. and R.W. Barratt. 1945. An improved grading system for measuring plant diseases. Phytopathology 35:655.

Hsam, S.L.K. and F.J. Zeller. 2002. Breeding for powdery mildew resistance in common wheat (Triticum aestivum L.), p. 256-267. In: 
Belanger, R.R., W.R. Bushnell, A.J. Dik, and T.L.W. Carver (eds.). The powdery mildews: A comprehensive treatise. APS Press, St. Paul, MN

Jahn, M., M.H. Munger, and J.D. McCreight. 2002. Breeding cucurbit crops for powdery mildew resistance, p. 256-267. In: Belanger, R.R., W.R. Bushnell, A.J. Dik, and T.L.W. Carver (eds.). The powdery mildews: A comprehensive treatise. APS Press, St. Paul, MN.

Jhooty, J.S. and W.E. McKeen. 1965. Studies on powdery mildew of strawberry caused by Sphaerotheca macularis. Phytopathology 55:281-285.

Jiwan, D., E.H. Roalson, D. Main, and D. Amit. 2013. Antisense expression of peach mildew resistance locus O (PpMlol) gene confers cross-species resistance to powdery mildew in Fragaria $\times$ ananassa. Transgenic Res. 22:1119-1131.

Kayihan, G.C., D.A. Huber, A.M. Morse, T.L. White, and J.M. Davis. 2005. Genetic dissection of fusiform rust and pitch canker disease traits in loblolly pine. Theor. Appl. Genet. 110:948-958.

Keller, M., S.Y. Rogiers, and H.R. Schultz. 2003. Nitrogen and ultraviolet radiation modify grapevines' susceptibility to powdery mildew. Vitis 42:87-94.

Landi, P., M.C. Sanguineti, S. Conti, and R. Tuberosa. 2001. Direct and correlated responses to divergent selection for leaf abscisic acid concentration in two maize populations. Crop Sci. 41:335-344.

Lifshitz, C., N. David, N. Shalit, S. Slotzky, Z. Tanami, Y. Elad, and N. Dai. 2007. Inheritance of powdery mildew resistance in strawberry lines from the Israeli germplasm collection, p. 70-74. In: Takeda, F., D.T. Handley, and E.B. Poling (eds.). Proc. 2007 North American Strawberry Symp. North Amer. Strawberry Growers Assn., Kemptville, Ontario, Canada.

Linde, M. and T. Debener. 2003. Isolation and identification of eight races of powdery mildew of roses (Podosphaera pannosa) (Wallr.: Fr.) de Bary and the genetic analysis of the resistance gene Rpp1. Theor. Appl. Genet. 107:256-262.

Lyngkjaer, M.F., A.C. Newton, J.L. Atzema, and S.J. Baker. 2000. The barley mlo-gene: An important powdery mildew resistance source. Agronomie 20:745-756.

Maas, J.L. 1998. Compendium of strawberry diseases. 2nd Ed. APS Press, St. Paul, MN.

Nelson, M.D., W.D. Gubler, and D.V. Shaw. 1995. Inheritance of powdery mildew resistance in greenhouse-grown versus field-grown California strawberry progenies. Phytopathology 85:421-424.

Ogden, A.B. and M.W. van Iersel. 2009. Southern highbush blueberry production in high tunnels: Temperatures, development, yield, and fruit quality during the establishment years. HortScience 44:18501856.

Pangga, I.B., J. Hanan, and S. Chakraborty. 2013. Climate change impacts on plant canopy architecture: Implications for pest and pathogen management. Eur. J. Plant Pathol. 135:595-610.

Peres, N.A. and J.C. Mertely. 2009. Powdery mildew of strawberries. 16 Apr. 2012. <http://edis.ifas.ufl.edu.lp.hscl.ufl.edu/pp129>.

Peries, O.S. 1962. Studies on strawberry mildew, caused by Sphaerotheca macularis (Wallr. Ex Fries) Jaczewski. 1. Biology of fungus. Ann. Appl. Biol. 50:211-224.

Pringle, G.J. and D.V. Shaw. 1998. Predicted and realized response of strawberry production traits to selection in differing environments and propagation systems. J. Amer. Soc. Hort. Sci. 123:61-66.

Ramming, D.W., F. Gabler, J.L. Smilanick, D.A. Margosan, M. CadleDavidson, P. Barba, S. Mahanil, O. Frenkel, M.G. Milgroom, and L. Cadle-Davidson. 2012. Identification of race-specific resistance in North American Vitis spp. limiting Erysiphe necator hyphal growth. Phytopathology 102:83-93.

Riedeman, E.S., M.A. Chandler, and W.F. Tracy. 2008. Divergent recurrent selection for vegetative phase change and effects on agronomic traits and corn borer resistance. Crop Sci. 48:17231731.

Salame-Donoso, T.P., B.M. Santos, C.K. Chandler, and S.A. Sargent. 2010. Effects of high tunnels on strawberry growth, yield, and postharvest quality in Florida. HortScience 45:503.

Santos, B.M., N.A. Peres, J.F. Price, V.M. Whitaker, P.J. Dittmar, S.M. Olson, and S.A. Smith. 2011. Strawbery production in Florida. 9 Aug. 2012. <http://edis.ifas.ufl.edu/pdffiles/cv/cv13400.pdf>.

Shaw, D.V., R.S. Bringhurst, and V. Voth. 1988. Quantitative genetic variation for resistance to leaf spot (Ramularia tulasnei) in California strawberries. J. Amer. Soc. Hort. Sci. 113:451-456.

Shaw, D.V., W.D. Gubler, J. Hansen, and K.D. Larson. 1997. Response to family selection for field resistance to Verticillium dahlia in California strawberries. J. Amer. Soc. Hort. Sci. 122:653655.

Shaw, D.V. and E.J. Sacks. 1995. Response in genotypic and breeding value to a single generation of divergent selection for fresh fruit color in strawberry. J. Amer. Soc. Hort. Sci. 120:270-273.

Stowe, K.A. and R.J. Marquis. 2011. Costs of defense: Correlated responses to divergent selection for foliar glucosinolate content in Brassica rapa. Evol. Ecol. 25:763-775.

Strand, L.L. 2008. Integrated pest management for strawberries. 2nd Ed. Regents Univ. of California, Oakland, CA.

Suthaparan, A., A. Stensvand, K.A. Solhaug, L.M. Mortensen, D.M. Gadoury, R.C. Seem, and H.R. Gislerod. 2012. Suppression of powdery mildew (Podosphaera pannosa) in greenhouse roses by brief exposure to supplemental UV-B radiation. Plant Dis. 96:16531660.

Valdes-Gomez, H., C. Gary, P. Cartolaro, M. Lolas-Caneo, and A. Calonnec. 2011. Powdery mildew development is positively influenced by grapevine vegetative growth induced by different soil management strategies. Crop Prot. 30:1168-1177.

Whitaker, V.M., L.F. Osorio, T. Hasing, and S. Gezan. 2012. Estimation of genetic parameters for 12 fruit and vegetative traits in the University of Florida strawberry breeding population. J. Amer. Soc. Hort. Sci. 137:316-324.

Willocquet, L., D. Colombet, M. Rougier, J. Fargues, and M. Clerjeau. 1996. Effects of radiation, especially ultraviolet B, on conidial germination and mycelial growth of grape powdery mildew. Eur. J. Plant Pathol. 102:441-449.

Wolff, K. and W. Vandelden. 1989. Genetic-analysis of ecological relevant morphological variability in Plantago-lanceolata L. IV. Response and correlated response to bidirectional selection for leaf angle. Heredity 62:153-160.

Xiao, C.L., C.K. Chandler, J.F. Price, J.R. Duval, J.C. Mertely, and D.E. Legard. 2001. Comparison of epidemics of Botrytis fruit rot and powdery mildew of strawberry in large plastic tunnel and field production systems. Plant Dis. 85:901-909.

Xu, X., J. Robinson, and D. Simpson. 2008. Interactions between isolates of powdery mildew (Podosphaera aphanis) and cultivars of strawberry, Fragaria $\times$ ananassa. Intl. Org. Biol. Integrated Control/ West Palaearctic Regional Section (OBC/WPRS) Bul. 39.

Zahavi, T., M. Reuveni, D. Scheglov, and S. Lavee. 2001. Effect of grapevine training systems on development of powdery mildew. Eur. J. Plant Pathol. 107:495-501. 